\title{
Is TQM more difficult to implement than other transformational strategies?
}

\author{
Carlos J.F. Cândido* and Sérgio P. Santos \\ CEFAGE-UE and Faculty of Economics, University of Algarve, Faro, Portugal.
}

\begin{abstract}
This paper aims to assess whether TQM is harder to implement than other business strategies. In order to accomplish this objective we have adopted a two-stage methodology. Firstly, we carried out an extensive review of the literature to identify the rates of TQM implementation failure estimated by researchers and practitioners. Secondly, we compared these rates with those estimated for other organisation-wide transformational efforts and explored the extent to which the obstacles to TQM implementation and to the implementation of other business strategies differ. Based on the literature reviewed and on the comparative analyses performed, we conclude that whilst it is widely acknowledged that the implementation of TQM can be a difficult task, significant uncertainty remains as to what the exact rate of failure is. Furthermore, the analyses suggest that the rates of failure and obstacles to TQM implementation are similar to those presented by other business strategies, and therefore, there seems to be no grounds to assume that TQM is more difficult to implement than other business strategies. These findings have implications for researchers and practitioners and open up several avenues for further research, which are also discussed in this paper.
\end{abstract}

Keywords: quality management, TQM, failure rate, success, strategy implementation.

\section{Introduction}

Total Quality Management (TQM) can be seen as a competitive advantage (Powell, 1995) and as a business-level strategy (Reed et al., 1996) which is clearly distinguishable from other business strategies for organisational improvement (Hackman and Wageman, 1995). It has also been looked at as an encompassing

\footnotetext{
* Corresponding author's address: Faculdade de Economia, Universidade do Algarve, Edifício 9, Campus de Gambelas, 8005-139 Faro, Portugal. E-mail: ccandido@ualg.pt.
} 
management philosophy (Dahlgaard and Dahlgaard-Park, 2006), which, as pointed out by Grant et al. (1994), poses a challenge to conventional management techniques and to the theories that underlie them. Implementation of the TQM strategy and philosophy might be one of the most complex activities that a company can attempt (Kanji, 1996). As emphasised by Sousa and Voss (2002: 105), TQM «cannot simply be grafted onto existing management structures and systems, and may require the redesign of work, the redefinition of managerial roles, the redesign of organizational structures, the learning of new skills by employees at all levels, and the reorientation of organizational goals».

TQM implementation can, indeed, be a difficult task (Dotchin and Oakland, 1992; Smith et al., 1994; Mersha, 1997; Yusof and Aspinall, 2000) and one which is often unsuccessful (Reger et al., 1994; Dahlgaard and Dahlgaard-Park, 2006). This has subjected the quality management field to growing criticism, and the early anecdotal success stories have been replaced over the years by a flood of critical findings (Wilkinson et al., 1994; Hendricks and Singhal, 1997; Kaynak, 2003). As a consequence, TQM has lost momentum and also users, both existing and potential. From one side, TQM organisations instead of adapting effectively to TQM initiatives started diverting their efforts and resources to other priorities (Grant et al., 1994; Soltani et al., 2005). From another side, the unsuccessful attempts to implement TQM reported in the press caused some managers who might otherwise have had an interest in implementing TQM to question the wisdom of utilising this management approach (Kaynak, 2003).

Accordingly, some researchers have reported a declining trend in the number of new companies adopting TQM, which indicates a certain degree of disillusionment with TQM and the consequent loss of popularity of this management philosophy (e.g., 
Terziovski et al., 1999; Prajogo and Brown, 2006; Dahlgaard-Park, 2011), in favour of other management strategies/systems (e.g., ISO 9000 certification).

All this has led to a generalised impression that implementing TQM is highly difficult (Sousa and Voss, 2002) and that it might fail to achieve a positive result on the performance of organisations. Recent research, however, has rendered this a controversial issue. Kaynak (2003) and Tarí et al. (2007), for example, found mixed and inconsistent results when analysing the empirical literature on the impact of TQM on organisational performance (see also Sousa and Voss, 2002).

The often cited disillusionment with TQM further suggests that TQM is seen as more difficult to implement than other organisation-wide transformational efforts. For example, it has been suggested that ISO 9000 can be a good first step for implementing TQM (e.g. Bradley, 1994; Yung, 1997; McAdam and McKeown, 1999), because it is less demanding to implement than TQM and it is perceived as 'superior' in terms of clarity of the content and evidence of achievement (Prajogo and Brown, 2006). In a similar vein, Grant et al. (1994), writing about TQM seem to imply that any business strategy aligned with conventional management practices is easier to implement than TQM. According to these authors:

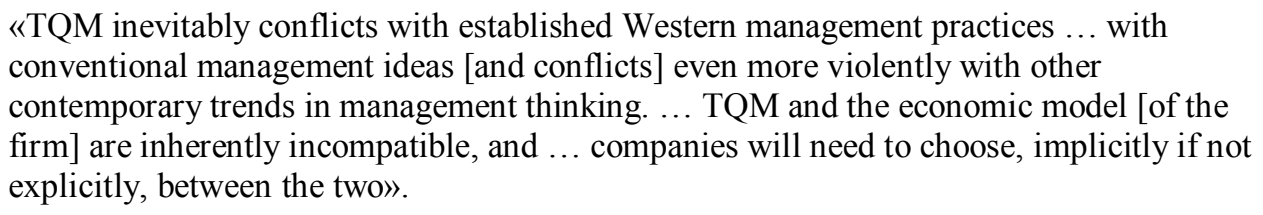
conventional management ideas [and conflicts] even more violently with other contemporary trends in management thinking. ... TQM and the economic model [of the firm] are inherently incompatible, and ... companies will need to choose, implicitly if not explicitly, between the two».

This suggests that, in order to implement TQM, 'conventional' western companies need to change much more than they need to when implementing other business strategies, which in turn implies that TQM is harder to implement. This view is shared by Carson et al. (2000) who compared 16 management techniques and rated TQM as the most radical technique and as one of the most difficult to implement. The problem, however, is that some of these views seem to be based more on conviction 
than on scientific facts. Furthermore, they are not consensual. There are other authors that support the view that TQM and business strategies, in general, are equally difficult to implement. For instance, Stoner et al. (1995) defends that we can find similarities between business strategy implementation and TQM implementation. Grant et al. (1994), whilst recognising that TQM might be more difficult to implement than other strategies, also argue that TQM implementation provides challenges similar to those involved in the management of other revolutionary transitions. And Miller (1997) submits that implementation success is not dependent on the kind of strategy that is being implemented. It is, therefore, imperative to conduct research which helps to shed light on the following question: Is TQM more difficult to implement than other transformational business strategies?

Clearly, it is widely accepted and largely demonstrated in the quality management literature that implementing TQM is difficult and a very time consuming task. Nevertheless, the literature on the implementation of other organisation-wide strategies seems to suggest that implementing these strategies can also be difficult. In fact, this problem of business strategy implementation is so generalised and acute that, according to Mockler (1995), there should be some kind of general model for strategy implementation, in the same way that there is a general model for strategy formulation.

The difficulty of successfully implementing new business strategies has been recognised by several authors (e.g., Alexander, 1985; Ansoff and McDonnell, 1990; Kaplan and Norton, 2001), and a 1989 Booz Allen study (cited by Zairi, 1995) concluded that most managers believe that the difficulty of implementing strategy surpasses that of formulating it. For example, the study found that $73 \%$ of managers believed that implementation is more difficult than formulation; $72 \%$ that it takes more time; and $85 \%$ that it is the part of the strategic planning process over which managers 
have least control. However, whilst it is consensual that implementing TQM or other transformational business strategies is not a straightforward task, there seems to exist a lack of consensus among researchers when it comes to express the real extent of the problem. In particular, it is not clear how difficult it is to implement TQM, in the same way that it is not clear whether TQM is harder to implement than other business strategies. Hence, more research is needed in order to contribute to a clarification of these issues. Because they are strongly interrelated issues, we need to address the question: How difficult is it to implement TQM?, before we can address our main research question.

In order to provide answers to these two research questions, an extensive review of the literature on TQM implementation is carried out to identify the rates of failure estimated by researchers and practitioners, and a comparative analysis between these rates and those estimated for other organisation-wide transformational efforts is presented. A comparative analysis between the obstacles to TQM implementation and to other business strategies implementation is also performed.

In pursuit of these objectives, the remainder of this paper is organised into several sections. It starts by introducing the concepts of transformational strategy and failure, which are instrumental to our study. It then discusses in further detail the methodology adopted in this research. The paper addresses each one of the research questions mentioned previously, and concludes by deriving implications for the literature and practice on TQM implementation.

\section{Transformational strategies and the concept of failure}

Several researchers have classified organizational change into a couple of distinct types, according to the extent of the change to be effected (Nutt, 1987; Nadler and Tushman, 1989; Dunphy and Stace, 1993; Hailey and Balogun, 2002). Nutt (1987) classifies the 
extent of change into two different types: modification of an existing strategy and implementation of a whole new strategy. Tichy and Devana (1986: viii-ix, 4-31) classify change into transactional change, i.e. small change to maintain balance of current operations in an organization, and transformational change, i.e. major changes in organizational vision, structure, practices, people and culture. Similarly, Nadler and Tushman (1989) separate incremental change, which focuses on a single component of the organization and aims to maintain global congruence, from strategic change, which involves all components of the organization and aims to create a new kind of organizational congruence. Dunphy and Stace (1993) define a scale of change with four types, from the local and less radical change to the global and more transformational. They define corporate transformation as a corporation-wide change «characterized by radical shifts in business strategy and revolutionary changes throughout the whole organization involving ... mission and core values ... distribution of power ... structures, systems ... procedures, workflows, communication networks ... decision making patterns [and] executives in key managerial positions». In the same vein, Hailey and Balogun (2002) and Balogun and Hailey (2008:21) look at the extent of change and define a transformational change as a global, discontinuous change «that challenges both the existing ways of thinking and behaving within an organisation, disrupting established activity patterns».

In the context of this research, the term transformational strategy is used broadly to explicitly encompass most of the characteristics mentioned in the definitions above. It is important to emphasise that although different researchers have defined transformational strategy in different ways, there is a great deal of common ground. Generally speaking, we will refer to a transformational change as a radical strategic 
change accompanied by modifications in many aspects of the organization, including power distribution and structure, tasks and processes, culture and people.

Failure, in turn, is a research issue that has been largely neglected by researchers (Mellahi and Sminia, 2009) and still lacks a specific definition (Mellahi and Wilkinson, 2004). Several approaches can be considered here, the classic, the evolutionary and others (Withington, 1993: 40). The evolutionary approach looks at failure (success) mainly as the death (survival) of the organization (Hannan and Freeman, 1977). The classic approach, based on the structure-conduct-paradigm (Mason, 1939), considers success/failure to depend on the attainment of «a competitive position or a series of competitive positions that lead to superior and sustainable performance» (Porter, 1991). The resource based perspective (Wernerfelt, 1984; Barney, 1991), in turn, sees success as the attainment of above normal performances. These performances are the result of a sustained competitive advantage, which depends on the ability of the organization to exploit its «most valuable, rare and costly to imitate resources» (Barney and Clark, 2007: 70).

Organizational success depends both on the choice of an adequate strategy and on the successful implementation of that strategy (Hussey, 1996). Unfortunately, not all successful strategies are adequate for their corresponding organizations and, because of that inadequacy, some 'successful' strategies have resulted in organizational failure. 'Successful strategy implementation' and 'organizational success' are different concepts (Hussey, 1996), with the latter being a more encompassing and relevant concept. A similar distinction between concepts can also be made between 'implementation process ease' and 'implementation process outcomes' (Bauer et al., 2005). In this study, we have focused on the latter: implementation process outcomes and organization success. 
The concept of success can be seen as a unidimensional concept or as a multidimensional construct. Some researchers have adopted a unidimensional approach to the measurement of success (e.g., Nutt, 1989; Hickson et al., 2003) whereas others have argued in favour of a multidimensional approach (Kaplan and Norton, 1996; Neely, 1998). A multidimensional approach can simultaneously incorporate several distinct performance measurements, which can be classified into two different types. One of the types includes the long-term, organization-wide, competitive-capability related performance measurements; the other type includes the internal, operational, short-term technical measurements (Voss, 1992). Performance variables can also be classified in terms of other aspects, such as the financial results, internal processes' efficiency, customers' satisfaction and organizational learning and development (Kaplan and Norton, 1996); operating performance, external perceptions and cultural aspects (Hudson et al., 2001); and cost, quality, flexibility, delivery and innovation (Pun and White, 2005).

Strategic change can vary in terms of the degree of the transformations introduced to the organization and in terms of the measurements used to assess its success and/or failure. This variability can create several difficulties in the assessment of TQM success and in the assessment of the implementation success of other kinds of strategies.

In order to allow comparisons between the different published studies to be made, we have adopted our own definition of failure. By failure we mean either a TQM or other transformational strategy was formulated but not implemented, or it was implemented but with poor results. 


\section{Methodology: Search strategy and selection criteria}

With the objective of finding answers to the two research questions previously identified, we conducted an extensive review of the literature and performed some statistical analysis. It is important to mention that since much research has already been done on the rates of failure and on the obstacles to implementation of both TQM and other business strategies, we reviewed the results of this research to try to understand firstly, how difficult it is to implement TQM and secondly, whether TQM is more difficult to implement than other business strategies. This review was performed in two phases, each one targeted at finding answers to each of the research questions.

In the first phase, we tried to identify all publications in scholarly journals at the EBSCO Host Research Databases that presented estimates for the rate of TQM implementation failure. The failure rate was used in this research as a measure of the difficulty in implementing a TQM strategy. In order to identify TQM failure rates we started by applying several search strings, including TQM and fail*, TQM and success*, TQM and implement*, quality and success* to keywords, title, and abstract of the publications at the EBSCO Databases. Within the set of publications that met the search criteria, we then identified all the papers from business journals. All those publications from the list that were not actually publications in the business area although they mentioned the search terms in the keywords, title or the abstract were omitted from further analysis. This step was followed by a careful analysis of the abstracts of all publications on this final list in order to assess their relevance for our research. We have considered relevant only studies that could present a percentage of failure (or of success) on TQM execution and/or that could discuss the most important obstacles to TQM implementation. For those publications considered to be relevant, we then analysed the full text in order to determine whether an estimate of the failure rate was 
provided. Bibliographic references in the selected papers were also used as a source to identify papers or other evidence not captured in our electronic database search.

In the second phase, the search strategy was expanded to include literature not only on TQM implementation but also on the implementation of other business strategies. In particular, we have tried to identify all publications at the EBSCO Host Research Databases that presented estimates for the rate of business strategy implementation failure and/or that discussed the reasons behind failure. The process adopted was, therefore, similar to the one adopted in the first stage of this research except that different string words were used including strateg* and fail*, strateg* and success*, strateg* and implement*, transfor* and fail*.

It is relevant to note, however, that the studies dealing with the implementation of TQM and of other business strategies have been authored by academics and practitioners, including consulting companies, and that not all of these studies have been published in academic journals. Therefore, a search strategy based exclusively on evidence documented in academic journals would be incomplete. Consequently, the final step in each of the phases above consisted of additional searches carried out on the Internet search engine Google, on the web-sites of major consulting companies, and on several national library on-line catalogues (England, U.S.A., Ireland, Scotland, Canada, Australia, and Portugal) which allowed the identification of some additional and relevant studies. Unfortunately, however, some of these studies were not available for consultation and it was not possible for us to gain access to either a hard or an electronic copy. Interestingly, many of these studies were authored by consulting companies (A.T. Kearney, Arthur D. Little, and Prospectus) and were abundantly quoted, even by reputed academic researchers. As part of our search strategy, we have also contacted by e-mail the consulting companies, the individual authors of the reports, when their names 
were publicly available, and the authors who have quoted those studies. In total, more than 45 e-mails were sent. In spite of all the efforts made to obtain copies of the studies, most of these efforts proved unfruitful. Many of the companies and authors contacted replied, but we did not succeed in obtaining the required information either because the studies were no more available (e.g. A.T. Kearney, A.D.L., Prospectus) or because of other reasons (e.g. B.C.G., McKinsey).

Therefore, the literature reviewed in this paper includes all the academic studies that have met the search criteria above and the consultancy studies that were relevant and available for consultation. The results of this search are presented and discussed in the next sections.

\section{TQM implementation failure}

The literature on the topic of TQM implementation failure is not scarce, however, the existing studies are mixed in terms of their features and this requires special care in comparing their results. The most significant features of the studies considered for this research are summarised in Table 1, which organises the information in five columns. The first column indicates the author(s) and year of the study and it is listed chronologically. The research method used to estimate the rates of failure/success and the variables against which such rates were assessed are described in the second and third columns, respectively. The fourth column indicates the estimated rate of failure presented by each study. Finally, the last column records some additional comments on each study.

Table 1 about here, please 
The most obvious conclusion that can be drawn from the analysis of Table 1 is that it is difficult to provide a straightforward answer to the question of how difficult to implement TQM is. The studies carried out so far by researchers and management consulting firms have obtained mixed results regarding the success and failure rates of TQM implementation, a view also expressed by Mohrman et al. (1995) and, more recently, by Sila (2007). In fact, as can be seen from the fourth column of Table 1, the range of variation of the estimates is remarkable. We can verify that the estimated rates of failure have ranged from as low as $7 \%$ to as high as $80 \%$. Therefore, the diversity of the estimates provided by the different authors over the years makes it very difficult to assess how difficult to implement TQM is and, in particular, to present an estimate for the likelihood of TQM success. Several reasons can be advanced for this difficulty in assessing the TQM failure rate.

Firstly, the studies discussing the success/failure rate of TQM implementation vary considerably in the amount of effort put into the estimation of the rate. In some of these studies the estimation of the rate of failure/success was their main objective (e.g. Wilkinson et al., 1994). In other studies, this objective was part of a broader research agenda (e.g. Taylor, 1997; Walsh et al., 2002; Taylor and Wright, 2003), while in others the rates of success/failure were presented as complementary information in an introduction or as an aside (e.g. Mohrman et al., 1995; Sila, 2007).

Secondly, TQM studies are not easily comparable because they use different criteria to define success/failure. Although all researchers but one relied on managements' perceptions of success, as can be seen in the third column of Table 1, different studies have used distinct criteria to define success/failure. Furthermore, whereas some studies have used a single criterion (e.g. Walsh et al., 2002; Sila, 2007) others have used multiple criteria (e.g. Wilkinson et al., 1994; Mohrman et al., 1995; 
Kunst and Lemmink, 2000). These differences can account for some of the discrepancies between estimations.

Thirdly, even assuming that two different studies on TQM success adopt exactly the same success criteria, these studies may not be easily comparable because the standards adopted in each of them for considering a TQM initiative as a success may vary considerably and are highly subjective. In most of the studies in Table 1, these standards are not even set and the researchers rely solely on the subjective assessments of the managers interviewed. A manager may consider that achieving $80 \%$ of a difficult target is a success, whereas other managers may consider this same percentage a moderate success, or even a failure.

Fourthly, different studies have used different research strategies to estimate the rate of success/failure of TQM implementation. Some have adopted a cross-sectional approach (e.g. Mohrman et al., 1995; Sila, 2007) while others have used a longitudinal one (e.g. Taylor and Wright, 2003). Some relied on surveys (e.g. Wilkinson et al., 1994; Mohrman et al., 1995; Sila, 2007), while others used a combination of two or more data collection methods (e.g. Kunst and Lemmink, 2000; Walsh et al., 2002; Taylor and Wright, 2003). Furthermore, these studies also vary in terms of the quality of their methodologies. In particular, studies conducted by consulting firms and by other practitioners have been criticised for lack of academic rigour (Hackman and Wageman, 1995) because of vested interests in the results of the studies (Powel, 1995) and because of the insufficient information provided on research methodology (Sousa and Voss, 2002). The quality of these studies might also have been affected by a lack of theoretical grounding (Flynn et al., 1994; Powell, 1995); a lack of objective statistical evidence (Hendricks and Singhal, 1997, 2001); a lack of testing for the reliability and validity of the measurement instruments (Flynn et al., 1994; Raghunathan et al., 1997); and a lack 
of control for factors that might have produced the observed performance differences (size of firms, industry, nationality, and adoption of TQM vs. non adoption) (Powell, 1995; Hendricks and Singhal, 1997).

Fifthly, some studies prove very difficult to obtain/access, in particular those undertaken by some management consulting firms such as A. T. Kearney and Arthur D. Little. Therefore, any conclusions taken from the estimates they have produced without a proper understanding of the context, methodology and results obtained might lack legitimacy and scientific rigour. In spite of this, it is common to find researchers (e.g. Holder and Walker, 1993; Smith et al., 1994; Zairi, 1995; Dow et al., 1999; Walsh et $a l ., 2002)$ that quote the results of these studies not because they have read the original work but because these estimates have been quoted by other researchers or in well known journals such as 'The Economist' or 'The Wall Street Journal'. Unfortunately, as pointed out by Taylor (1997) this has lead some of these studies to be widely misquoted and misunderstood.

Sixthly, the degree of change introduced into the organization by the implementation of a TQM strategy may vary from organization to organization. For some organizations, TQM implementation may require more and deeper changes than for other organizations. For instance, organizations that are ISO 9000 certified may find it easier to implement TQM (Bradley, 1994). As the degree of the change required to implement TQM decreases, so does the difficulty in the implementation, and the probability of success may tend to increase (Balogun and Hailey, 2008: 72). Unfortunately, the studies in Table 1 have implicitly considered TQM implementation as an equally difficult initiative for every organization, and did not consider the degree of change as a variable to measure. Needless to say that assessing the degree of change is also a difficult task in itself. 
Lastly, but not least, it is important to bear in mind that different studies were carried out at different moments in time. Therefore, while an estimated rate of failure could reflect the real situation when the study was undertaken, it might not be appropriate to apply it to different time periods. Some of the rates of failure that have been quoted by some authors in recent years (e.g. Soltani et al., 2005) are based on studies carried out sometime ago (e.g. A.T. Kearney, 1992) and, therefore, they may no longer reflect the real difficulty of TQM implementation.

Unless these factors (effort, criteria, standards, research strategies, degree of change, context and time) which are rarely discussed in the literature are accounted for, any attempts to present an overall estimate for the real success/failure rate of TQM strategy implementation are likely to fail or are of little practical value. This is an important finding as it indicates that some of the high failure rates quoted in the literature are highly speculative, to say the least. It also points to the need for researchers to design measurement systems that adequately reflect the success or failure of TQM initiatives (Kollberg, Dahlgaard and Brehmer, 2007; Dahlgaard, Pettersen and Dahlgaard-Park, 2011). Considering the number and variety of factors mentioned above, it is recommended that researchers intending to quote TQM success/failure rates adopt one of two alternatives. They can use a strict definition for success and in doing so they have to be very clear about what the assumptions underlying the rates they are quoting are. Alternatively, they can adopt a loose definition for success and in doing so they have to consider all the relevant studies documenting TQM success/failure rates, which will necessarily include high and low estimates. Whilst the first alternative would provide the most robust conclusions, it seems to be absent from most of the literature that quote very high failure rates. The second alternative, which we have used in this 
study, does not seem to have been properly followed by previous studies either, as some important estimates seem to have been largely ignored so far.

A systematic review of the literature based on the second strategy allows us, however, to reach very valuable conclusions. In particular, it shows that the prevalent idea of the extreme difficulty of TQM implementation has no strong, consistent support in current empirical studies. As shown in Table 1, although there are studies reporting high failure rates, there are others presenting much lower estimates. Indeed, a careful analysis of the values presented in Table 1 clearly indicates that the high rates of failure - around $80 \%$ - that are frequently taken for granted in the TQM literature should neither continue to be considered consensual, nor indisputable. Additionally, the analysis of the rates estimated over time seems to exhibit a downward trend (Figure 1). This finding is consistent with our previous observation that high rates of failure cannot continue to be considered acceptable consensual estimates. It is important to emphasise that these conclusions remain valid even when the rates estimated by the consulting companies are withdrawn from the analysis.

Figure 1 about here, please

Independently of the 'real' success/failure rate, and despite the fact that success rates seem to have improved over time, it is reasonable to conclude that the number of TQM initiatives that fail is still considerably higher than would be desirable. Many companies implement TQM, but fail to achieve a positive result, which ultimately means that the implementation was a failure. This is not to say that implementing TQM is doomed to failure, but simply that not all companies seem to be benefiting from it and that implementation fails on too many occasions. This suggests that organisations either 
need better TQM implementation guidelines or need to make better use of the existing ones. The need for better implementation processes has been widely acknowledged by researchers (e.g. Dean and Bowen, 1994; Mockler, 1995; Barney, 2001; Hickson et al., 2003) and research on how to avoid implementation obstacles and improve implementation has been underway for many years (e.g. Stanislao and Stanislao, 1983; Alexander, 1985; Ansoff and McDonnell, 1990; Kotter, 1995; Beer and Eisenstat, 2000; Miller et al., 2004; Stadler and Hinterhuber, 2005). It is, therefore, important to assess the extent to which these guidelines account for some of the improvements achieved in TQM implementation as well as to understand the reasons why so many initiatives still fail.

Although it can be acknowledge that implementing TQM is a difficult task, an important question still remains. Is TQM more difficult to implement than other business strategies? An answer to this question is discussed in what follows.

\section{The difficulty of implementing TQM}

In order to assess whether TQM is more difficult to implement than other business strategies we first compared TQM failure rates with those presented by other business strategies and then we assessed the extent to which the obstacles to their implementation differ.

Eight studies were identified that present or discuss rates of failure for business strategies in general. The estimated rates are presented in Table 2.

Table 2 about here, please 
Similarly to TQM failure rates, it is possible to observe from Table 2 that the estimated rates of failure for other business strategies differ remarkably between studies, ranging from $28 \%$ to $90 \%$. While no definitive conclusions can be drawn regarding the failure rate of general business strategies, for the same reasons presented previously, it is possible to observe from Table 2 that the rate range for general business strategy is not very different from the one presented in Table 1 for TQM, although the latter is slightly wider. Therefore, the results in Table 2 do not seem to support the view that TQM is more difficult to implement than business strategy in general. The same conclusion can be reached if we compare the mean values of the rates. In fact, the mean value computed for TQM (37.7) is not higher than that calculated for other business strategies (54.8).

Whilst it might be argued that data limitations prevent us from drawing definite conclusions that the rates of TQM failure are similar to the ones of other business strategies, it is important to emphasise that the scientific evidence supporting the presumption that TQM is harder to implement, is considerably weaker or even nonexistent. Therefore, we believe that is safer to conclude that there are no grounds to support the view that TQM is more likely to fail than other business strategies. This belief is strengthened when we compare the obstacles behind the failure of TQM and other strategic initiatives.

Researchers in the fields of strategic management and TQM have long shown considerable interest in identifying the obstacles that may impede successful implementation of business strategy and TQM, respectively. As a result of this interest, several check-lists of mistakes that should be avoided have been produced. Table 3 provides a comprehensive summary of the implementation obstacles that can be found in these fields. They have been arranged so that, whenever possible, each line in the 
table may exhibit a match between the TQM implementation obstacles and the corresponding obstacles in the strategic management literature.

Table 3 about here, please

As can be observed, Table 3 represents a match to the twenty-one TQM implementation obstacles identified. With the exception of the last two obstacles, which are somehow specific to TQM, all other matches exhibit exact correspondences. Note, for instance, that the obstacle which has been considered as the most important one for TQM - management commitment (Kanji and Asher, 1993; Kanji, 1996) - has an exact match in the field of strategic management.

We cannot exclude the possibility that some previous cross-fertilization might have occurred between the two fields (TQM and business strategy), which would have led to a greater similarity between the two lists of obstacles. However, this crossfertilization would have strengthened our contention that obstacles are similar to both types of strategy implementation, which in turn would provide more evidence in favour of a similar degree of implementation difficulty. In fact, the comparison in Table 3 shows that the impediments that may occur and prevent a successful TQM implementation are identical to the obstacles that may impede a successful implementation of any other business strategy. This seems to suggest that the answer to the second research question of this study is that TQM is no more difficult to implement than other general business strategies. We, consequently, submit the proposition that TQM is no harder to implement than other transformational strategies. 


\section{Discussion and implications for research and management}

Three major conclusions can be drawn from the analysis carried out in the preceding sections. The first conclusion is that the current state of affairs does not allow us to precisely estimate how likely it is for a TQM initiative to be successful. Currently available estimates span from $7 \%$ to $80 \%$, a wide range of variability with no predictive capability. The higher rates are frequently cited in the literature, although there is no reason to consider these better estimates than the lower ones. On the contrary, it can be argued that the lower rates are more trustworthy, because they are more recent estimates and have been calculated by independent researchers, whereas the higher rates are older estimates and originated mostly from consulting companies. According to Powell (1995), consulting companies have vested interests in divulging higher rates of failure. This discussion of the failure rates has an obvious implication for managers and researchers. It indicates that TQM should recover some of the management attention it had in the past and should not continue to be dismissed on the basis of an unfounded belief that it is too difficult.

The second conclusion is that both TQM and other general business strategies seem to face identical difficulties of implementation. In particular, our literature review and analysis of published empirical research on rates of failure and on implementation obstacles suggests a lack of support to the widely shared underlying assumption that TQM is harder to implement than other organisation-wide transformational efforts. This finding also has implications for researchers as it points to an unfounded prevalent assumption and to the need to change the current idea that TQM is harder to implement than other strategic initiatives. Furthermore, by suggesting that the obstacles and degree of implementation difficulty experienced by TQM and other business strategies is similar, this research indicates that increased cross-fertilization between the fields of 
TQM and strategic management would be beneficial. However, the implications of these findings extend also to practicing managers. Had our investigation confirmed that TQM was harder to implement and this research would have lend support for those managers who are inclined to abandon TQM in favour of other strategies believed to be 'easier'. Such a conclusion would have also motivated the development of specific advice for those who wish to implement TQM - the more obvious advice being that they should proceed more carefully than they do when implementing other strategies. However, since this research did not find evidence to support the current general conviction that TQM is harder to implement than other strategies, it does not support the apparent management disillusionment with TQM. This finding suggests, therefore, that managers should not abandon TQM in favour of other business strategies. It is our belief that TQM is probably being currently dismissed by many companies in favour of other alternatives even before an informed decision can be made. At a time when there is no empirical evidence to support that choice, TQM may be a perfectly viable alternative solution to many of these companies' strategic challenges. Researchers, consultants and practitioners continuing to quote the higher rates of failure and stating that TQM is harder to implement than other strategic initiatives are reproducing inaccurate beliefs. As we have demonstrated these beliefs have no unequivocal empirical support in the literature and may be contributing to more companies dismissing TQM as a strategic alternative.

The third conclusion is that, whilst it is not consensual what the TQM failure rate is and although success rates seem to have improved over time, the number of TQM initiatives that fail is still unacceptable. It is important to emphasise that, with the exception of a few studies that present very small estimates, most of the research carried 
out so far estimate that one third or more of the TQM initiatives are unsuccessful. The same conclusion applies to business strategy in general.

Several factors can help explain the high rates of failure estimated over the years. Firstly, and probably most importantly, it is that companies do really fail too much and need better implementation guidelines. The need for better implementation processes has been widely acknowledged by researches (e.g., Dean and Bowen, 1994) and research on how to avoid implementation obstacles and improve implementation has been underway for many years (e.g., Stanislao and Stanislao, 1983; Alexander, 1985; Ansoff and McDonnell, 1990; Kotter, 1995; Beer and Eisenstat, 2000; Miller et al., 2004; Stadler and Hinterhuber, 2005). The solution to unsuccessful implementation can involve one or a combination of three possibilities: better application (e.g., Nutt, 1999; Hrebiniak, 2006) of the universal principles of TQM (Crosby, 1979: 1; Deming, 1982: 23, 130; Juran, 1986, 1999: 2.5); better adaptation of the principles of TQM to the context of the organisation, through a selection of the most appropriate quality strategy content (Reed et al., 1996) and mix of quality practices (Sitkin et al., 1994; Zhao et al., 2004; Shrivastava et al., 2006); and/or modification of the adverse internal context of the organization to the TQM practices to be adopted (Sousa and Voss, 2001). It is important to mention, however, that although companies do fail too much, some of them see failure as a part of their organisational strategic learning. A failure can provide useful insights that, given certain circumstances, may become advantageous in the marketplace (Mintzberg, 1987; Krogh and Vicari, 1993; Sitkin et al., 1994).

Secondly, and as pointed out by Powell (1995), it cannot be neglected that some overestimation might exist, particularly in those rates presented by consulting firms. Most of the higher failure rates estimated origin from consulting firms, lending some support to the 'theory' of overestimation. In fact, most of their research was negatively 
affected by a lack of theoretical grounding, clear methodology, objective statistical evidence, reliability and validity testing, and of control for extraneous factors (Flynn et al., 1994; Powell, 1995; Raghunathan et al., 1997; Hendricks and Singhal, 1997, 2001; Sousa and Voss, 2002).

Thirdly, TQM is usually considered a major transformational strategy which is difficult to implement. That difficulty helps to explain why there are high failure rates. However, looking at the degree of change introduced by TQM into an organization as a variable - not an identical constant for every organization contemplating the possibility of implementing TQM - might also contribute to explain the wide range of rates of failure encountered.

The degree of transformation required can be seen as a variable influenced by factors such as 'how receptive the culture of the organization is' or 'how many quality systems the organization already has in place' when it decides to implement TQM. In a company where culture is more receptive and where some sort of incipient quality systems are already in place, the implementation may require fewer changes and is probably easier (Briscoe et al., 2005).

ISO 9000 certification, for instance, can be a good first step to facilitate the implementation of TQM (Bradley, 1994). Implementing ISO 9000 as a first step for TQM is a way of dividing change into more manageable steps, putting basic quality systems in place, contributing to a more receptive culture, and lowering the degree of change required to subsequently implementing TQM. Consequently, for an organization that has already implemented ISO 9000, implementing TQM may seem less demanding, and the rate of failure may be lower for that organization than for organizations deciding to implement TQM without any previous preparation. 
Unfortunately, most companies that seek ISO 9000 certification do not have in mind TQM implementation. They frequently feel pushed to adopt the ISO standard and their motivation is not to seek organizational improvement (e.g., Briscoe et al., 2005). Consequently, ISO 9000 is not frequently used as a successful means to facilitate TQM implementation (Prajogo and Brown, 2006).

Fourthly, differences in the concepts of success adopted can also account for the coexistence of very high and very low estimates. As previously discussed, it is possible to distinguish between 'technical success' and 'competitive success' (Voss, 1992), between 'success as process ease' and 'success as process outcomes' (Bauer et al., 2005) and, similarly, between 'implementation success' and 'organisational success' (Hussey, 1996). The higher rates of failure estimated may depend on a stricter sense of success adopted by researchers. Estimates of technical success and success as process ease may be higher than estimates of success as process outcomes or organizational competitive success in the marketplace, since more internal and external contingencies can affect the latter types of success. In tables 1 and 2 we have reported failure rates mainly from a stricter perspective of 'competitive success' or of 'organisational success'.

Fifthly, the coexistence of very high and very low estimates in the literature may be a consequence of the impact of several contingency factors, such as, for instance, turbulence, size of firms, industry, time, and so on. Research has shown that contingency factors have lead to different conclusions regarding the impact of TQM practices on firm performance (Saad and Siha, 2000). Sila (2007), for instance, explored the extent to which context and contingency factors affect TQM implementation, but did not find supporting evidence. In case we are able to prove that context and contingency factors mediate the relationship between the implementation of TQM and 
firms' performance (e.g., Bauer et al., 2005), then these factors might also explain why previous estimates of TQM failure vary so widely and help to inform researchers on how to better estimate the likelihood of success.

Finally, and as previously pointed out, it is important to bear in mind that most of the higher estimates for the rates of failure come from studies carried out in the 1990s and may no longer be valid, due to the advances made in recent years in the field of TQM. As shown in Figure 1, recent estimates tend to be lower than the earlier ones. In fact, contrary to Taylor's (1996: 237) conviction that the failure rates exhibited an upward trend, our compilation of secondary data, seems to suggest that they actually exhibit a downward trend.

Several explanations can be advanced for the apparent improvement observed on TQM implementation:

- Researchers and consultants have identified many of the obstacles that might impede a successful TQM implementation (e.g., Gallacher, 1991; Juran and Gryna, 1993; Wilkinson et al., 1994; Kanji, 1996). Identification of the obstacles and of how they interact may have improved the methods for managing the transition to a quality culture and the corresponding rates of success.

- Companies that kept their TQM initiatives over the years had more time to extract increased benefits from it. Powell (1995) found empirical evidence to conclude that time since adoption contributed to a greater satisfaction with TQM implementation. Similarly, Prajogo and Brown (2006: 562) concluded that «success derived from TQM implementation is significantly associated with the time since adoption». There have been, however, some mixed results in this regard. For instance, Rungtusanatham et al. (2005), in investigating whether or not the amount of TQM experience explains differences between companies in different countries, found 
some evidence that time since adoption contributed to a better internalization of the elements of TQM, but neither to a higher employee fulfilment nor to a better customer satisfaction.

- TQM philosophy and techniques have been in practice for a long time (Sila, 2007). Familiarity with this philosophy and techniques may have increased over time and knowledge may have accumulated that narrowed the knowledge gap between companies in general (Sila, 2007) and helped them to implement TQM with more successful results. Taylor and Wright (2003) hypothesised that the general level of understanding of TQM among companies has improved over time, and that this increased understanding has contributed to a higher level of implementation success. They found empirical support for the hypothesis that companies with a better understanding of TQM experienced higher perceived implementation success. Hendricks and Singhal (2001), however, did not observe any significant differences between the performance of companies implementing TQM at distinct timings (years).

- Companies may have imitated early successful adopters of TQM benefiting from their experience, a view which is also shared by Sila (2007). However, it is not consensual that imitating early good practices will necessarily lead to good results. As suggested by Westphal et al. (1997), the organisational performance of late adopters of TQM could be detrimentally affected because they simply imitate early adopters instead of customizing TQM practices to their unique needs and capabilities. Westphal et al. (1997) further hypothesised that all firms could ultimately abandon TQM programmes as the poor performance outcomes of later adopters would reduce their legitimacy. 
- Companies have become more aware to the importance of customisation of the TQM principles and techniques to their characteristics and to the context in which they work, instead of blind adoption of the general undifferentiated principles early outlined by TQM Gurus such as Crosby (1979), Deming (1982) and Juran (1951, 1986, 1988, 1989). Deming (1982) declared that the principles of quality management are universal and that they apply anywhere, from small organizations to large ones, and from the service industry to manufacturing. In the same vein, Juran (1986) proposed a universal way of thinking about quality, which fits all functions, all levels, all product lines and all industries. More recently, however, Sousa and Voss (2002) concluded that difficulties and problems with the implementation of TQM may result from a mismatch between this universal form of TQM and the particular organisational context of the organisation. The high rates of failure that have been estimated also led researchers to suggest that TQM could be context-dependent (Sitkin et al., 1994; Sila, 2007) and that, consequently, TQM implementation should be tailored to the characteristics of the organization and of its environment (Benson et al. 1991; Mintzberg and Westley, 1992; Dean and Bowen, 1994; Reger et al., 1994; Sitkin et al., 1994; Saad and Siha, 2000; Sousa and Voss, 2001, 2002; Sila 2007). This view has been supported by some researchers such as Hendricks and Singhal (2001) and Zhao et al. (2004). Zhao et al. (2004) provided empirical evidence in favour of contingent relationships among quality management practices, context, and performance; while Hendricks and Singhal (2001) concluded that many organisational factors moderate the benefits of TQM implementation. However, this new TQM customisation approach has not been fully supported by the existing empirical research on the effects of organisational context on quality management practices and on organisational 
performance. As pointed out by Sila (2007: 84), to date, existing studies «did not provide conclusive evidence for the validity of either the universal or contextdependent approach to TQM». For instance, several researchers that have studied the impact of country of origin on TQM practices and performance have provided inconsistent results. Some concluded that country of origin has no effect (e.g. Rao et al., 1997; Rungtusanatham et al., 2005; Sila, 2007), while others concluded the opposite (e.g. Adam et al., 1994, 1997; Raghunathan et al., 1997; Tata et al., 2000; Tarí et al., 2007).

Independently or in combination, each of these factors might help explain the apparent improvement on TQM implementation success observed in recent years. This is, however, an issue also needing further research. In particular it is fundamental to assess, first, weather the apparent improvement observed is a fact, and second, which factors have most contributed to it. A better understanding of these issues could play an important role in implementing TQM more successfully.

\section{Conclusion}

In this paper we have aimed to assess whether TQM is harder to implement than other business strategies. To this effect we have addressed two major questions: Firstly, we have discussed what the real rate of TQM failure is. Based on an extensive review of the literature, and in particular, on the estimates presented by researchers and practitioners, we have concluded that it is extremely difficult to know with an acceptable degree of precision what the current failure rate of TQM initiatives is. This difficulty is explained mostly by the wide variability of the estimates available, which can be attributable to differences in research methodologies and in organisational contexts. In particular, the variability in the estimates obtained so far seems to be a result of overestimation, 
differences in the concepts of success being adopted by researchers, differences in the samples and methodologies used, differences in organisational learning behaviours and differences in contextual factors affecting organisations and their environments.

Secondly, we have explored whether TQM implementation is more difficult than the implementation of other business strategies. Two comparative analyses were performed to find an answer to this question. Based on a comparison between the failure rates of TQM and of other business strategies and on a comparison of the major obstacles that prevent a successful implementation of each of these types of strategies, we have concluded that there is no conclusive evidence supporting the view that TQM is more difficult to implement than other strategies. In particular, the comparative analyses performed showed that the rates of failure that have been estimated by researchers in the TQM and strategic management fields as well as the obstacles to the implementation of both types of strategy are similar. These findings seem to suggest, therefore, that the degree of TQM implementation difficulty is very similar to that experienced in the implementation of other organization-wide transformational efforts.

However, care needs to be taken in interpreting these findings. In particular, it is important to be aware that the analysis carried out was based on three strong assumptions. Firstly, a single variable was used to measure the degree of success of a strategic initiative. A single variable or an aggregate variable was used to allow for an easy comparison. Secondly, the comparisons were based on data that were generated within distinct research settings and which cannot be indisputably combined into a single sample. The fact that we have adopted a loose concept for failure allowed us, however, to minimize this limitation. Finally, the sample used in this research was formed through several searches at the EBSCO Host Research Databases, which means that our data were not the result of a random sampling method. Therefore, some data 
might have been excluded, not because they were not randomly selected but simply because they did not meet up the search criteria.

Notwithstanding the implications of these assumptions, which impose some limitations to this study, its findings are very relevant to both researchers and practitioners. While this research cannot unequivocally demonstrate a scientific truth, it does offer, however, a serious attempt to expose and question the deeply engrained belief that TQM often does not lead to the intended results and that it is harder to implement than other general business strategies. This study submitted that there is currently no consistent empirical evidence to support this belief and that reproducing it in new TQM publications may deter more companies from adopting it. Finally, this study opens new avenues for further research. In particular, it points that it is imperative to carry out carefully planned research to: (1) determine how difficult is it to implement TQM nowadays; (2) assess how does this difficulty compare and contrast with the one experienced by other specific strategies (e.g. ISO 9000); and (3) explore whether the literature on TQM and on other strategies implementation could benefit from a more intense cross-fertilization. A better understanding of these issues is fundamental to assess whether practising managers have wrongly become disillusioned with TQM.

\section{Acknowledgement}

The authors would like to thank the helpful comments on an earlier draft of this paper that were made by David S. Morris and Andrew Thomas, both from Newport Business School, University of Wales, and Nelson António and António Teixeira, both from ISCTE, Lisbon. We would also like to thank the anonymous referee for the insightful comments and helpful suggestions. Funding support for this research was provided by the Faculdade de Economia, Universidade do Algarve, Newport Business School, 
University of Wales, and Fundação para a Ciência e a Tecnologia

(SFRH/BSAB/863/2008 and FEDER/POCI 2010).

\section{References}

A.T. Kearney, in association with the TQM Magazine (1992). Total quality: Time to take off the rose tinted spectacles. Kempston: IFS Publications.

Adam Jr, E.E., Corbett, L.M., \& Rho, B.H. (1994). Quality improvement practices in Korea, New Zealand and the USA. International Journal of Quality \& Reliability Management, 11(7), 6-18.

Adam Jr., E.E., Corbett, L.M., Flores, B.E., Harrison, N.J., Lee, T.S., Rho, B.H., Ribera, J., Samson, D., Westbrook, R., (1997). An international study of quality improvement approach and firm performance. International Journal of Operations \& Production Management, 17(9), 842-873.

Alexander, L.D. (1985). Successfully implementing strategic decisions. Long Range Planning, 18(3), 91-97.

Ansoff, H.I., \& McDonnell, E. (1990). Implanting strategic management. New York: Prentice Hall International.

Arthur D. Little (1992). Executive caravan TQM survey summary. Cambridge, MA: Arthur D. Little Corporation.

Balogun, J. \& Hailey, V.H. (2008). Exploring Strategic Change. Edinburgh Gate: Prentice Hall.

Barney, J. (1991). Firm resources and sustained competitive advantage. Journal of Management, 17(1), 99-120.

Barney, J.B. (2001). Is the resource-based 'view' a useful perspective for strategic management research? Yes. Academy of Management Review, 26(1), 41-56.

Barney, J.B. \& Clark, D.N. (2007) Resource-Based Theory: Creating and Sustaining Competitive Advantage. Oxford: Oxford University Press.

Bauer, J., Falshaw, R., \& Oakland, J.S. (2005). Implementing business excellence. Total Quality Management, 16(4), 543-553.

Beer, M., \& Eisenstat, R.A. (2000). The silent killers of strategy implementation and learning. Sloan Management Review, 41(4), 29-40.

Benson, P.G., Saraph, J.V., Schroeder, R.G. (1991). The effects of organizational context on quality management: an empirical investigation. Management Science, 37(9), 1107-1124.

Bradley, M. (1994). Starting total quality management from ISO 9000. The TQM Magazine, 6(1), 50-54.

Briscoe, J.A., Fawcett, S.E., \& Todd, R.H. (2005). The implementation and impact of ISO 9000 among small manufacturing enterprises. Journal of Small Business Management, 43(3), 309-330.

Carson, P.P., Lanier, P.A., Carson, K.D., \& Guidry, B.N. (2000). Clearing a path through the management fashion jungle: some preliminary trailblazing. Academy of Management Journal, December, 43(6), 1143-1158.

Charan, R., \& Colvin, G. (1999). Why CEOs Fail. Fortune, 139(12), 68-78.

Corboy, M., \& Corrbui, D. (1999). The seven deadly sins of strategy implementation. Management Accounting, November, 77(10), 29-30.

Crosby, P.B. (1979). Quality is free - The art of making quality certain. New York: McGraw-Hill. 
Dahlgaard, J.J. \& Dahlgaard-Park, S.M. (2006). Lean production, six sigma quality, TQM and company culture. The TQM Magazine, 18(3), 263-281.

Dahlgaard, J.J., Pettersen, J. \& Dahlgaard-Park, S.M. (2011). Quality and lean health care: a system for assessing and improving the health of healthcare organisations. Total Quality Management and Business Excellence, 22(6), 673689.

Dahlgaard-Park, S.M. (2011). The quality movement: where are you going? Total Quality Management and Business Excellence, 22(5), 493-516.

Dean, J.W., \& Bowen, D.E. (1994). Management theory and total quality management: improving research and practice through theory development. Academy of Management Review, 19(3), 392-418.

Deming, W.E. (1982). Out of the Crisis. Cambridge, Massachusetts: The MIT Press.

Dobni, C.B., \& Luffman, G. (2003). Determining the scope and impact of market orientation profiles on strategy implementation and performance. Strategic Management Journal, 24(6), 577-585.

Dotchin, J.A., \& Oakland, J.S. (1992). Theories and concepts in TQM. Total Quality Management, 3(2), 133-145.

Dow, D., Samson, D., \& Ford, S. (1999). Exploding the myth: do all quality management practices contribute to superior quality performance?. Production and Operations Management, Spring, 8(1), 1-27.

Dunphy, D. \& Stace, D. (1993). The strategic management of corporate change. Human Relations, 46(8), 905-920.

Flynn, B.B., Schroeder, R.G., \& Sakakibara, S. (1994). A framework for quality management research and an associated measurement instrument. Journal of Operations Management, 11(4), 339-366.

Gallacher, H. (1991). Avoiding the pitfalls. The TQM Magazine, June, 3(3), 157-160.

Gijo, E.V., \& Rao, T.S. (2005). Six Sigma implementation - hurdles and more hurdles. Total Quality Management, 16(6), 721-725.

Grant, R.M., Shani, R., \& Krishnan, R. (1994). TQM's challenge to management theory and practice. Sloan Management Review, 35(2), 25-35.

Gray, D.H. (1986). Uses and misuses of strategic planning. Harvard Business Review, 64(1), 89-97.

Hackman, J.R., \& Wageman, R. (1995). Total quality management: empirical, conceptual, and practical issues. Administrative Science Quarterly, 40(2), 309342.

Hailey, V.H. \& Balogun, J. (2002). Devising context sensitive approaches to change: the example of Glaxo Wellcome. Long Range Planning, 35, 153-178.

Hannan, M.T. \& Freeman, J. (1977). The population ecology of organizations. American Journal of Sociology, 82(5), 929-964.

Harari, O. (1997). Ten reasons why TQM doesn't work. Management Review, January, 81(1), 38-44.

Hendricks, K.B., \& Singhal, V.R. (1997). Does implementing an effective TQM program actually improve operating performance? Empirical evidence from firms that have won quality awards. Management Science, September, 43(9), 1258-1274.

Hendricks, K.B., \& Singhal, V.R. (2001). Firm characteristics, total quality management, and financial performance. Journal of Operations Management, 19(3), 269-285. 
Hickson, D.J., Miller, S.J., \& Wilson, D.C. (2003). Planned or Prioritized? Two Options for Managing the Implementation of Strategic Decisions?. Journal of Management Studies, 40(7), 1803-1836.

Holder, T., \& Walker, L. (1993). TQM Implementation. Journal of European Industrial Training, 17(7), 18-21.

Hrebiniak, L.G. (2006). Obstacles to effective strategy implementation. Organizational Dynamics, 35(1), 12-31.

Hudson, M., Smart, A. \& Bourne, M. (2001). Theory and practice in SME performance measurement systems. International Journal of Operations \& Production Management, 21(8), 1096-1115.

Hussey, D. (1996). A Framework for implementation. In Hussey, D. (Ed.), The Implementation Challenge. Chichester: John Wiley \& Sons.

Judson, A.S. (1991). Invest in a high-yield strategic plan. The Journal of Business Strategy, July/August, 12(4), 34-39.

Juran, J.M. (1951). Quality Control Handbook. New York: McGraw-Hill.

Juran, J.M. (1986). The quality trilogy: a universal approach to managing for quality. Quality Progress, 19(8), 19-24.

Juran, J.M. (1988). Juran on Planning for Quality. New York: The Free Press.

Juran, J.M. (1989). Juran on Leadership for Quality: An Executive Handbook. New York: The Free Press.

Juran, J.M. (1993). Why quality initiatives fail. Journal of Business Strategy, 14(4), July/August, 35-38.

Juran, J.M. (1999). How to think about quality. In Juran, J.M., \& Godfrey, A.B. (Eds.), Juran's Quality Handbook (2.1-2.18). New York: McGraw-Hill International Editions.

Juran, J.M., \& Gryna, F.M. (1993). Quality Planning and Analysis. New York: McGraw-Hill International Editions.

Kanji, G.K. (1996). Implementation and Pitfalls of Total Quality Management. Total Quality Management, 7(3), 331-343.

Kanji, G.K., \& Asher, M. (1993). Total quality management process: A systematic approach. Abingdon: Carfax Publishing Company.

Kaplan, R.S., \& Norton, D.P. (1996). The Balanced Scorecard - Translating Strategy into Action. Boston, MA: Harvard Business School Press.

Kaplan, R.S., \& Norton, D.P. (2001). The strategy-focused organization - How balanced scorecard companies thrive in the new business environment. Boston: Harvard Business School Press.

Kaynak, H. (2003). The relationship between total quality management practices and their effects on firm performance. Journal of Operations Management, 21(4), 405-435.

Kendrick, J. (1992). Companies continue to embrace quality programs - but has TQ generated more enthusiasm than results?. Quality, May, 31(5), 13.

Kiechel, W. (1982). Corporate strategists under fire. Fortune, December, 106(13), 3439.

Kiechel, W. (1984). Sniping at strategic planning. Planning Review, May, 8-11.

Kollberg, B., Dahlgaard, J.J. \& Brehmer, P. (2007). Measuring lean initiatives in health care services: issues and findings. International Journal of Productivity and Performance Management, 56(1), 7-24.

Kotter, J.P. (1995). Leading change: why transformation efforts fail. Harvard Business Review, 73(2), 59-67. 
Krogh, G., \& Vicari, S. (1993). An autopoiesis approach to experimental strategic learning. In Lorange, P., Chakravarthy, B., Roos, J., \& Van de Ven, A. (Eds.), Implementing Strategic Processes, Change Learning \& Co-operation (394-410). Cambridge: Basil Blackwell.

Kunst, P., \& Lemmink, J. (2000). Quality management and business performance in hospitals: a search for success parameters. Total Quality Management, 11(8), 1123-1133.

Mankins, M.C., \& Steele, R. (2005). Turning great strategy into great performance. Harvard Business Review, 83(7/8), 65-72.

Mason, E.S. (1939) Price and production policies of large-scale enterprise. American Economic Review, 29(March), 61-74.

Mathews, J., \& Katel, P. (1992). The cost of quality. Newsweek, September 7, 120(10), 48-49.

McAdam, R., \& McKeown, M. (1999). Life after ISO 9000: an analysis of the impact of ISO 9000 and total quality management on small business in Northern Ireland. Total Quality Management, 10(2), 229-241.

McKinsey (2006). Improving strategic planning: a McKinsey survey. The McKinsey Quarterly, July/August, 1-11. Retrieved from www.mckinseyquarterly.com.

Mellahi, K. \& Sminia, H. (2009). The frontiers of strategic management research. International Journal of Management Reviews, 11(1), 1-7.

Mellahi, K. \& Wilkinson, A. (2004). Organizational failure: a critique of recent research and a proposed integrative framework. International Journal of Management Reviews, 5/6(1), 21-41.

Mersha, T. (1997). TQM implementation in LDCs: driving and restraining forces. International Journal of Operations \& Production Management, 17(2), 164-183.

Miller, S. (1997). Implementing strategic decisions: four key factors. Organisation Studies, 18(4), 577-602.

Miller, S., Wilson, D., \& Hickson, D. (2004). Beyond planning strategies for successfully implementing strategic decisions. Long Range Planning, 37(3), 201-218.

Mintzberg, H. (1987), Crafting strategy. Harvard Business Review, 65(4), 66-75.

Mintzberg, H., \& Westley, F. (1992). Cycles of organizational change. Strategic Management Journal, 13(1), 39-59.

Mockler, R.J. (1995). Strategic management: the beginning of a new era, In Hussey, D.E. (Ed.), Rethinking Strategic Management (1-41). Chichester: John Wiley \& Sons.

Mohrman, S.A., Tenkasi, R.V., Lawler III, E.E., Ledford Jr., G.E. (1995). Total quality management: practice and outcomes in the largest US firms. Employee Relations, 17(3), 26-41.

Nadler, D.A. \& Tushman, M.L. (1989). Organizational frame bending: principles for managing reorientation. The Academy of Management Executive, III, 194-204.

Nayak, P.R. (2008). Personal correspondence with P. Ranganath Nayak, former VicePresident of Arthur D. Little and one of the authors of the study by Arthur D. Little (1992).

Neely, A. (1998). Measuring Business Performance - Why, What and How. London: The Economist Books.

Nutt, P.C. (1987). Identifying and appraising how managers install strategy. Strategic Management Journal, 8(1), 1-14.

Nutt, P.C. (1989). Selecting tactics to implement strategic plans. Strategic Management Journal, 10(2), 145-161. 
Nutt, P.C. (1999). Surprising but true: half the decisions in organizations fail. Academy of Management Executive, 13(4), 75-90.

O'Brien, C., \& Voss, C.A. (1992). In search of quality - An qssessment of 42 british organizations using the criteria of the baldrige award. Operations Management paper 92/02, London Business School, U.K.

Porter, M.E. (1991). Towards a dynamic theory of strategy. Strategic Management Journal, 12(Winter), 95-117.

Powell, T.C. (1995). Total quality management as competitive advantage: a review and empirical study. Strategic Management Journal, 16(1), 15-37.

Prajogo, D.I., \& Brown, A. (2006). Approaches to adopting quality in SMEs and the impact on quality management practices and performance. Total Quality Management, 17(5), 555-566.

Prospectus Strategy Consultants (1996). Profiting from increased consumer sophistication - a survey of retail financial services in Ireland and Great Britain. Prospectus Strategy Consultants, U.K.

Pun, K.F. \& White, A.S. (2005). A performance measurement paradigm for integrating strategy formulation: a review of systems and frameworks. International Journal of Management Reviews, 7(1), 49-71.

Raghunathan, T.S., Rao, S.S., Solis, L.E. (1997). A comparative study of quality practices: USA, China and India. Industrial Management and Data Systems, 97(5), 192-200.

Rao, S.S., Raghunathan, T.S., Solis, L.E. (1997). A comparative study of quality practices and results in India, China, and Mexico. Journal of Quality Management, 2(2), 235-250.

Reed, R., Lemak, D.J., \& Montgomery, J.C. (1996). Beyond process: TQM content and firm performance. Academy of Management Review, 21(1), 173-202.

Reger, R.K., Gustafson, L.T., Demarie, S.M., Mullane, J.V. (1994). Reframing the organization: why implementing total quality is easier said than done. Academy of Management Review, 19(3), 565-584.

Rungtusanatham, M., Forza, C., Koka, B.R., Salvador, F., Nie, W. (2005). TQM across multiple countries: convergence hypothesis versus national specificity arguments. Journal of Operations Management, 23(1), 43-63.

Saad, G.H., \& Siha, S. (2000). Managing quality: critical links and a contingency model. International Journal of Operations \& Production Management, 20(10), 1146-1163.

Shin, D., Kalinowski, J.G., \& El-Enein, G.A. (1998). Critical implementation issues in total quality management. Advanced Management Journal, Winter, 63(1), 1014.

Shrivastava, R.L., Mohanty, R.P., \& Lakhe, R.R. (2006). Linkages between total quality management and organisational performance: an empirical study for Indian industry. Production Planning \& Control, 17(1), 13-30.

Sila, I. (2007). Examining the effects of contextual factors on TQM and performance through the lens of organisational theories: an empirical study. Journal of Operations Management, 25(1), 83-109.

Sirkin, H.L., Keenan, P., \& Jackson, A. (2005). The hard side of change management. Harvard Business Review, 83(10), 109-118.

Sitkin, S.B., Sutcliffe, K.M., \& Schroeder, R.G. (1994). Distinguishing control from learning in total quality management: a contingency perspective. Academy of Management Review, 19(3), 537-564. 
Smith, S., Tranfield, D., Foster, M., \& Whittle, S. (1994). Strategies for managing the TQ agenda. International Journal of Operations \& Production Management, 14(1), 75-88.

Soltani, E., Lai, P., \& Gharneh, N.S. (2005). Breaking through barriers to TQM effectiveness: lack of commitment of upper-level management. Total Quality Management, 16(8\&9), 1009-1021.

Sousa, R., \& Voss, C.A. (2001). Quality management: universal or context dependent?. Production and Operations Management, 10(4), 383-404.

Sousa, R., \& Voss, C.A. (2002). Quality management re-visited: a reflective review and agenda for future research. Journal of Operations Management, 20(1), 91-109.

Sriparavastu, L., \& Gupta, T. (1997). An empirical study of just-in-time and total quality management principles implementation in manufacturing firms in the USA. International Journal of Operations \& Production Management, 17(12), 1215-1232.

Stadler, C., \& Hinterhuber, H.H. (2005). Shell, Siemens and DaimlerChrysler: leading change in companies with strong values. Long Range Planning, 38(5), 467-484.

Stanislao, J., \& Stanislao, B.C. (1983). Dealing with resistance to change. Business Horizons, 26(4), 74-78.

Stoner, J.A.F., Freeman, R.E., \& Gilbert Jr., D.R. (1995). Management. London: Prentice-Hall International Editions.

Tarí, J.J., Molina, J.F., \& Castejón, J.L. (2007). The relationship between quality management practices and their effects on quality outcomes. European Journal of Operational Research, 183(2), 483-501.

Tata, J., Prasad, S., Motwani, J. (2000). Benchmarking quality management practices: US versus Costa Rica. Multinational Business Review, 8(2), 37-42.

Taylor, W.A. (1996). Sectoral differences in total quality management implementation: the influence of management mind-set. Total Quality Management, 7(3), 235248.

Taylor, W.A. (1997). Leadership challenges for smaller organisations: self-perceptions of TQM implementation. Omega - The International Journal of Management Science, 25(5), 567-579.

Taylor, W.A., \& Wright, G.H. (2003). A longitudinal study of TQM implementation: factors influencing success and failure. Omega - The International Journal of Management Science, 31(2), 97-111.

Terziovski, M., Sohal, A., \& Moss, S. (1999). Longitudinal analysis of quality management practices in Australian organizations. Total Quality Management, 10(6), 915-926.

The Economist (1992). The cracks in quality, The Economist, April 18, 69-70.

Tichy, N.M. \& Devanna, M.A. (1986). The Transformational Leader. New York: John Wiley \& Sons.

Voss, C.A. (1992). Successful innovation and implementation of new processes. Business Strategy Review, 3(1), 29-44.

Walsh, A., Hughes, H., Maddox, D.P. (2002). Total quality management continuous improvement: is the philosophy a reality? Journal of European Industrial Training, 26(6), 299-307.

Wernerfelt, B. (1984). A Resource based view of the firm. Strategic Management Journal, 5(2), 171-180.

Westphal, J.D., Gulati, R., Shortell, S.M. (1997). Customization or conformity? An institutional and network perspective on the content and consequences of TQM adoption. Administrative Science Quarterly, 42(2), 366-394. 
Whittington, R. (1993). What is Strategy - and does it matter? London: Routledge. Wilkinson, A., Redman, T., \& Snape, E. (1994). The problems with quality management - the view of managers: findings from an Institute of Management survey. Total Quality Management, 5(6), 397-406.

Yung, W.K.C. (1997). The values of TQM in the revised ISO 9000 quality system. International Journal of Operations \& Production Management, 17(2), 221-230.

Yusof, S.M., \& Aspinall, E. (2000). TQM implementation issues: review and case study. International Journal of Operations \& Production Management, 20(6), 634-655.

Zairi, M. (1995). Strategic Planning Through Quality Policy Deployment: a Benchmarking Approach, in Kanji, G.K. (Ed.), Total Quality Management: Proceedings of the First World Congress (207-215). London: Chapman \& Hall.

Zhao, X., Yeung, A.C.L., \& Lee, T.S. (2004). Quality management and organizational context in selected service industries of China. Journal of Operations Management, 22(6), 575-587. 
Table 1. Studies estimating TQM implementation failure rates.

\begin{tabular}{|c|c|c|c|c|}
\hline Study & Method & Variable & Rate of failure & Obs. \\
\hline $\begin{array}{l}\text { A. T. Kearney } \\
(1992)^{*}\end{array}$ & Survey. Sample of over 100 British firms (according to The Economist, 1992). & n.a. & $80 \% \dagger$ & $\begin{array}{l}\text { This study has been abundantly cited, e.g., The Economist (1992), Wilkinson et al. (1994), } \\
\text { and Soltani } \text { et al. (2005). Unfortunately, we could not find a copy. We searched A. T. } \\
\text { Kearney's web site, several national library on-line catalogues (e.g. England, U.S.A., } \\
\text { Ireland, Scotland, Canada, Australia, and Portugal), and Emerald web site (editor of the } \\
\text { TQM Magazine). We asked a copy by e-mail sent to A.T. Kearney, to Emerald and also to } \\
\text { the authors who quoted the study. All this proved unfruitful. †† } \dagger\end{array}$ \\
\hline $\begin{array}{l}\text { Arthur D. Little } \\
(1992) *\end{array}$ & $\begin{array}{l}\text { Telephone survey conducted by a subsidiary of A.D.L., combining questions } \\
\text { formulated by a number of clients, including the parent company, into a single } \\
\text { short questionnaire (Nayak, 2008). Sample of } 500 \text { American companies from the } \\
\text { manufacturing and service industries (The Economist, 1992). Other details of the } \\
\text { methodology not released publicly (Powell, 1995). }\end{array}$ & $\begin{array}{l}\text { Perceived impact } \\
\text { of TQM on } \\
\text { company } \\
\text { competitiveness } \\
\text { (Nayak, 2008) }\end{array}$ & $67 \%$ & $\begin{array}{l}\text { This study has been abundantly quoted, e.g., The Economist (1992), Mathews and Katel } \\
\text { (1992) and Powell (1995). Unfortunately, we could not find a copy. We searched ADL's } \\
\text { web site and several national library on-line catalogues. We asked a copy by e-mail sent to } \\
\text { ADL, to the authors, and also to authors who quoted the study. All this proved unfruitful. } \\
\text { Personal correspondence exchanged with one of the authors provided some information } \\
\text { (Nayak, 2008). }+\dagger\end{array}$ \\
\hline $\begin{array}{l}\text { Rath \& Strong } \\
\text { Management } \\
\text { Consulting } \\
(1992)^{*}\end{array}$ & $\begin{array}{l}\text { Survey. Sample size of } 95 \text { top managers from Fortune } 500 \text { companies (according } \\
\text { to Kendrick, 1992). }\end{array}$ & $\begin{array}{l}\text { Perception of the } \\
\text { degree to which } \\
\text { the objectives } \\
\text { were met } \\
\text { (Kendrick, 1992) }\end{array}$ & $55 \%$ & $\begin{array}{l}\text { This study has been abundantly cited, e.g., Kendrick (1992) and Harari (1997). } \\
\text { Unfortunately, we could not find a copy. We searched the Rath \& Strong web site and on } \\
\text { several national library on-line catalogues. We asked a copy by e-mail sent to Rath \& } \\
\text { Strong and also to the authors who quoted the study. All this proved unfruitful. †† We have } \\
\text { used the data in Kendrick (1992) and considered a failure when less than } 50 \% \text { of the total } \\
\text { quality programme objectives were met. }\end{array}$ \\
\hline $\begin{array}{l}\text { Wilkinson et al. } \\
\text { (1994) }\end{array}$ & $\begin{array}{l}\text { Postal questionnaire sent to managers from all management levels and functions of } \\
\text { public and private sector organizations of the UK and foreign owned companies. } \\
\text { Several industries covered. Sample of } 880 \text { managers. Descriptive statistics only. }\end{array}$ & $\begin{array}{l}\text { Perceived overall } \\
\text { success of QM } \\
\text { programme }\end{array}$ & $53 \%$ & \\
\hline $\begin{array}{l}\text { Mohrman et al. } \\
(1995)\end{array}$ & $\begin{array}{l}\text { Mail survey sent to the CEOs of the } 500 \text { largest service and } 500 \text { largest industrial } \\
\text { companies in the USA. Sample size: } 290 \text {. No rigorous control on who filled the } \\
\text { questionnaire. Descriptives and statistical tests. }\end{array}$ & $\begin{array}{l}\text { Perceived impact } \\
\text { on } \\
\text { competitiveness, } \\
\text { profitability and } \\
\text { employee } \\
\text { satisfaction }\end{array}$ & $33 \%$ & \\
\hline $\begin{array}{l}\text { Sriparavastu and } \\
\text { Gupta (1997) }\end{array}$ & $\begin{array}{l}\text { Postal questionnaire sent to } 500 \text { plant managers selected from the population of } \\
\text { USA's manufacturing companies (SIC codes } 20 \text { to } 39 \text { ) employing between } 50 \text { and } \\
3000 \text { people. Pilot test of } 100 \text { questionnaires, with a } 29 \% \text { response rate, allowed } \\
\text { modification and addition of some questions. Sampling method not identified. } \\
\text { Sample of } 154 \text { managers from several levels and departments ( } 31 \% \text { response rate). } \\
\text { Inconsistent responses analysed to eliminate ambiguity. Descriptives and statistical } \\
\text { tests associated with research hypotheses. }\end{array}$ & $\begin{array}{l}\text { Percentage of } \\
\text { companies that } \\
\text { abandoned TQM }\end{array}$ & $8 \%$ & $\begin{array}{l}\text { We calculated the failure rate using the data provided in the paper. Only companies that had } \\
\text { implemented TQM were considered. Hence: } 0.052 / 0.680=0.0764 \text {. }\end{array}$ \\
\hline
\end{tabular}


Table 1. Studies estimating TQM implementation failure rates (continuation)

\begin{tabular}{|c|c|c|c|c|}
\hline Study & Method & Variable & Rate of failure & Obs. \\
\hline Taylor (1997) & $\begin{array}{l}\text { Postal questionnaire mailed to the most senior executive of over } 2000 \text { firms in } \\
\text { Northern Ireland. Stratified sample of } 682 \text { firms representative in terms of sector } \\
\text { and size of firm; } 113 \text { of these companies had a TQM program. Descriptives and } \\
\text { some statistical tests associated with research questions. }\end{array}$ & $\begin{array}{l}\text { Perceived } \\
\text { financial impact of } \\
\text { TQM }\end{array}$ & $8 \%$ & $\begin{array}{l}\text { We calculated the failure rate using the data provided in the paper. A null or a marginal } \\
\text { financial impact was considered a failure. Hence: } 0.96(0.01+0.63 \times 0.12)=0.082 \text {. }\end{array}$ \\
\hline $\begin{array}{l}\text { Unknown, cited } \\
\text { by Shin et al. } \\
\text { (1998) }\end{array}$ & n.a. & n.a. & $60 \%-67 \%$ & $\begin{array}{l}\text { Shin, Kalinowski and El-Enein (1998) do not provide sufficient information to identify the } \\
\text { original empirical study. We asked two of the authors by e-mail to indicate the correct } \\
\text { reference, but received no answer until this moment. }\end{array}$ \\
\hline $\begin{array}{l}\text { Kunst and } \\
\text { Lemmink (2000) }\end{array}$ & $\begin{array}{l}\text { Questionnaires sent to general managers and quality managers. } 36 \text { items used to } \\
\text { measure the criteria of the European Quality Award. Follow-up in-depth } \\
\text { interviews with quality managers. Population of } 850 \text { hospitals in U.K., Spain and } \\
\text { Netherlands, including public and private, as well as general and university } \\
\text { hospitals. Sample of } 227 \text { hospitals, } 125 \text { from the U.K., } 46 \text { from Spain and } 56 \text { from } \\
\text { the Netherlands. Descriptives and statistical test associated with research } \\
\text { hypotheses. }\end{array}$ & $\begin{array}{l}\text { Average of } \\
\text { managers' } \\
\text { perceptions of } \\
\text { occupation rate, } \\
\text { financial results } \\
\text { and market share }\end{array}$ & $23 \%$ & $\begin{array}{l}\text { We calculated the failure rate using the data provided in the paper. For this calculation, a } \\
\text { low performance was considered a failure. Hence: } 51 \text { low performers in a total of } 223 \\
\text { usable responses, corresponds to a failure rate of } 0,228699 \text {. Average performers were } 99 \text {, } \\
\text { and high performers were } 73 \text {. There is one limitation in the procedure used here, which is } \\
\text { related to the fact that there is no guarantee that all hospitals where TQM hospitals, and } \\
\text { even those that were TQM hospitals, were in different stages of the implementation } \\
\text { process. }\end{array}$ \\
\hline $\begin{array}{l}\text { Walsh et al. } \\
(2002)\end{array}$ & $\begin{array}{l}\text { Postal questionnaires sent to the senior managers of } 170 \text { selected medium and } \\
\text { large-sized companies in Ireland. Selection method not specified. First } \\
\text { questionnaire: sample size } n=72,51 \text { with a TQM programme. Second } \\
\text { questionnaire: sample size } n=28 \text {, all of which TQM firms. Follow up calls to } \\
\text { clarify responses and secondary data. Descriptive statistics only. }\end{array}$ & $\begin{array}{l}\text { Perceived overall } \\
\text { success of TQM } \\
\text { programme }\end{array}$ & $7 \%$ & \\
\hline $\begin{array}{l}\text { Taylor and } \\
\text { Wright (2003) }\end{array}$ & $\begin{array}{l}\text { Longitudinal study over a period of } 5 \text { years of a cohort of } 109 \text { TQM firms in } \\
\text { Northern Ireland. Postal questionnaire mailed to CEOs or Managing Directors. } \\
\text { Further details obtained through } 25 \text { follow up interviews. Stratified sample } \\
\text { representative in terms of sector and size of firm. Descriptives and statistical tests } \\
\text { associated with research hypotheses. }\end{array}$ & $\begin{array}{l}\text { Perceived TQM } \\
\text { outcome/success }\end{array}$ & $41 \%$ & $\begin{array}{l}\text { The rate of failure corresponds to the proportion of unsuccessful and of discontinued TQM } \\
\text { programs }\end{array}$ \\
\hline Sila (2007) & $\begin{array}{l}\text { Mail survey sent to a selected key informant of each of the } 2000 \text { manufacturing } \\
\text { and service companies randomly selected from the ASQ mailing list. Sample size: } \\
\text { 286. Responses tested for non response bias and for scale reliability and validity. } \\
\text { Descriptives and statistical tests associated with research hypotheses. }\end{array}$ & $\begin{array}{l}\text { Perceived success } \\
\text { of the TQM } \\
\quad \text { program }\end{array}$ & $14 \%$ & \\
\hline
\end{tabular}

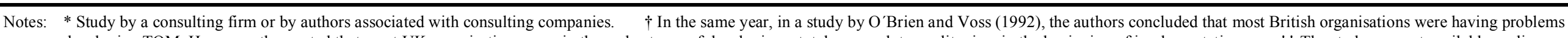
developing TQM. However, they noted that most UK organisations were in the early stages of developing a total approach to quality, i.e., in the beginning of implementation. $\begin{array}{ll}\text { We did not received replies to our e-mails or the replies were negative. } & \text { n.a. Information not available. }\end{array}$ 
Table 2. Studies estimating general business strategy implementation failure rates.

\begin{tabular}{lc}
\hline \multicolumn{1}{c}{ Study * } & Rate of failure \\
\hline Kiechel (1982, 1984) & $90 \%$ \\
Gray (1986) and Judson (1991) (Gray-Judson-Howard, Inc.) & $51 \%-90 \% \dagger$ \\
Prospectus Strategy Consultants (1996), cited by Corboy and Corrbui (1999) & $70 \%$ \\
Unknown, cited by Sirkin, Keenan and Jackson (2005) (BCG) & $67 \%$ \\
Nutt (1999) & $50 \%$ \\
Mankins and Steele (2005) (Marakon Associates) & $33 \%$ \\
Nutt (1987) & $30 \%$ \\
McKinsey (2006) & $28 \%$
\end{tabular}

Notes: * A study by Charan and Colvin (1999) was not included in this table intentionally. This study estimated that $70 \%$ of the strategies that fail, do so, because of bad implementation. Although this estimate has been interpreted as a business strategy rate of failure (e.g. Kaplan and Norton, 2001: 1), this is not appropriate as the study seems to consider only those strategies that were unsuccessful, and indicates the proportion of which failed because of bad implementation, among other possible causes. † For all calculations, we used the average of the two rates of failure indicated. 
Table 3. A comparison between obstacles to strategy implementation.

\section{Obstacles to the implementation of TQM *}

Lack of customer orientation

Lack of leadership, quality of management

Lack of senior management commitment and their visible participation, lack of people's real involvement, people see quality as a management fad

Reliance on simple exhortation to introduce TQM

Weak proof of need for change

Ignoring evidence that contradicts current views

Failure to anticipate scepticism and resistance to change

Lack of communication and dialogue, lack of coordination, barriers between departments
Vision, strategy and goals are not clear or contradictory

Obstacles to the implementation of business strategy, in general $\uparrow$

Inadequate marketing orientation

Unclear vision or bad strategy, conflicting priorities

Inadequate leadership, no development of leadership down-the-line

Lack of management commitment, decisions made and plans developed without participation, no personnel empowerment, no identification with the change

Poor choice of method for introducing change

Not establishing a good enough sense of urgency

Selective attention and retention of pieces of information

No collection of data on barriers, no assessment of readiness for change, lack of a behavioural diagnosis

Inadequate information systems, insufficient information available, no sincere discussion about obstacles to implementation, ineffective coordination

Lack of generally accepted and precise definition of TQM Insufficient information available, insufficient detail components about implementation tasks, inadequate information systems

Fear of change, risk avoidance, complacency, resistance to change

Lack of quality education, inadequate quality of employees, insufficient number of black belts

Organisational structure, lack of an infrastructure for quality, institutionalized quality management

Lack of time, work overloads, competing initiatives, quality is not a top priority

Limited resources

Lack of clarity in measurement systems, non-availability of data, no recognition nor rewards

Failure to start small and learn from pilot projects

Reluctance to change, fear of failure, fear of loss of power, status, freedom and benefits

Inadequate training, inadequate timing of training, insufficient current skills

Structural rigidity, bureaucracy, no institutionalisation of the change in structure and culture, no consolidation of organisational improvements

Day-to-day activities take all available time, conflicting priorities

Limited or committed resources

Inadequate performance measurement systems, inadequate feedback information, control systems reinforce status quo

Lack of previous trials, experimentation or pilot projects

Adoption of isolated TQM techniques instead of a holistic Not changing systems, structures and policies that don't approach

External events (e.g., recession)

Quality management seen as a 'quick fix' or magic box, impatience to get results, emphasis in short-term goals, critical success factors ignored, lack of constancy of purpose

fit the vision

Unanticipated external events

No link between strategic and daily objectives, personnel attention distracted from implementation activities, declaring victory (success) too soon, no institutionalisation of the change in structure and culture, inadequate performance management systems

Declaring success too soon, inadequate performance management

Satisfaction with customer satisfaction, which could impede exceeding customer satisfaction

Notes: * Compiled from Gallacher (1991), Juran (1993), Juran and Gryna (1993), Kanji and Asher (1993), Wilkinson et al. (1994), Kanji (1996), Soltani et al. (2005) and Gijo and Rao (2005). † Compiled from Alexander (1985), Ansoff and McDonnell (1990), Kotter (1995), Beer and Eisenstat (2000), Kaplan and Norton (2001), Dobni and Luffman (2003). 


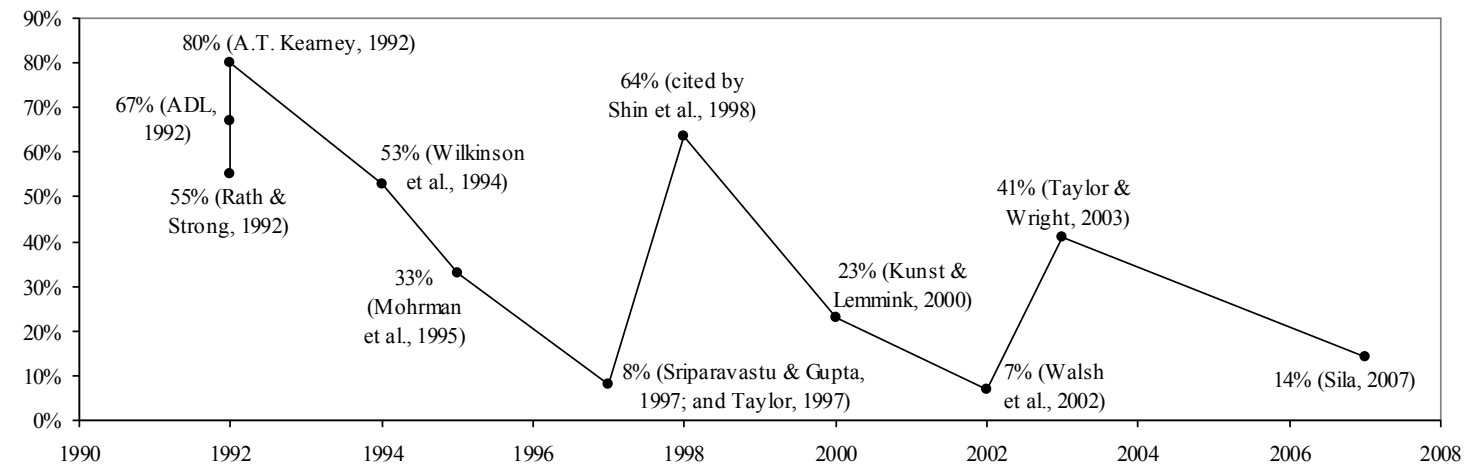

Figure 1 - TQM estimated failure rates over the years. 